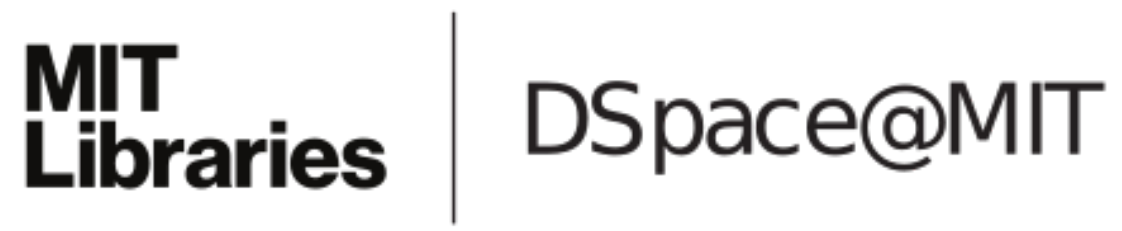

\author{
MIT Open Access Articles
}

Modeling of internal mechanical failure of all-solid-state batteries during electrochemical cycling, and implications for battery design

The MIT Faculty has made this article openly available. Please share how this access benefits you. Your story matters.

Citation: Bucci, Giovanna et al. "Modeling of Internal Mechanical Failure of All-Solid-State Batteries During Electrochemical Cycling, and Implications for Battery Design." Journal of Materials Chemistry A 5, 36 (August 2017): 19422-19430 @ 2017 The Royal Society of Chemistry

As Published: http://dx.doi.org/10.1039/C7TA03199H

Publisher: Royal Society of Chemistry (RSC)

Persistent URL: http://hdl.handle.net/1721.1/118458

Version: Original manuscript: author's manuscript prior to formal peer review

Terms of use: Creative Commons Attribution-Noncommercial-Share Alike 


\title{
Modeling of internal mechanical failure of all-solid-state batteries during electrochemical cycling, and implications for battery design
}

\author{
Giovanna Bucci ${ }^{\mathrm{a}, *}$, Tushar Swamy ${ }^{\mathrm{a}}$, Yet-Ming Chiang ${ }^{\mathrm{a}}$, W. Craig Carter ${ }^{\mathrm{a}}$ \\ ${ }^{a}$ Massachusetts Institute of Technology, Department of Materials Science and Engineering - 77 Massachusetts Avenue, Cambridge, MA \\ 02139-4307 USA
}

\section{N Abstract}

This is the first quantitative analysis of mechanical reliability of all-solid state batteries. Mechanical degradation of the solid electrolyte (SE) is caused by intercalation-induced expansion of the electrode particles, within the constrains of a dense microstructure. A coupled electro-chemo-mechanical model was implemented to quantify the material properties that cause a SE to fracture. The treatment of microstructural details is essential to the understanding of stresslocalization phenomena and fracture. A cohesive zone model is employed to simulate the evolution of damage. In the numerical tests, fracture is prevented when electrode-particle's expansion is lower than $7.5 \%$ (typical for most Li-intercalating compounds) and the solid-electrolyte's fracture energy higher than $G_{c}=4 \mathrm{~J} \mathrm{~m}^{-2}$. Perhaps counterintuitively, the analyses show that compliant solid electrolytes (with Young's modulus in the order of $\mathrm{E}_{S E}=15 \mathrm{GPa}$ ) are more prone to micro-cracking. This result, captured by our non-linear kinematics model, contradicts the speculation that sulfide SEs are more suitable for the design of bulk-type batteries than oxide SEs. Mechanical degradation is linked to the battery power-density. Fracture in solid Li-ion conductors represents a barrier for Li transport, and accelerates the decay of rate performance.

\section{Introduction}

Li-ion batteries that use solid electrolyte materials (SEs) in place of traditional liquid electrolytes could achieve high energy density while avoiding safety issues surrounding liquid electrolyte flammability. Solid electrolytes with conductivity approaching that of liquid electrolyte have recently been discovered [1 7. Despite fast growing interest in all-solid-state batteries (ASSBs), many challenges remain in both manufacturing and reliability of the technology.

In ASSBs, the solid-electrolyte is responsible for binding the active material and establishing conductive paths for $\mathrm{Li}$ ions. However, the formation of micro-cracks within the solid electrolyte is expected to reduce its effective ionic conductivity. Additionally, low porosity solid-state systems are expected to be more prone to mechanical degradation if not designed to accommodate intercalation-induced deformations. As fracture degrades the microstructure, paths for lithium diffusion become more tortuous and the battery power-density decreases. Microscale defects and inhomogeneities in battery microstructures would interfere with Li transport and accelerate the decay of battery performance. Furthermore, at sufficiently high current densities, micro-cracks may provide a pathway for Li dendrite growth, eventually causing the cell to short 8 .

\footnotetext{
${ }^{*}$ Corresponding author

Email address: bucci@mit.edu (Giovanna Bucci )
}

We employ a fully coupled electro-chemo-mechanical model to investigate fracture mechanisms in composite solid-state electrodes. Treatment of microstructural details and local variability [9] enables the study of stress localization caused by particle misalignment and non-smooth features. A cohesive zone model (CZM) is employed to simulate the evolution of damage [10. The detrimental effect of fracture on Li-ion flux is also taken into account by the CZM. We quantify the conditions under which fracture occurs, caused by the chemical expansion of electrode particles. Fracture is the result of regions of shear and tensile stresses formed during electrochemical cycling.

The role of intercalation-induced stress (also called Vegard's stress) on the mechanical failure of electrode particles has been previously studied [17 50]. Among these studies, only Bower and Guduru 19 employed a fully coupled chemo-mechanical model to simulate fracture of a simplified electrode microstructure. To our knowledge, ours is the first model to quantitatively assess mechanical reliability of all-solid state batteries, and predict the extension of fracture caused by electrochemical cycling.

The mechanical properties of solid electrolyte materials have not received much attention and very limited experimental chemo-mechanical properties are available. Measurements collected in Table 1 reveal a wide range of values for Young's modulus. In particular, sulfide SEs tend to be much more compliant than oxide electrolytes. The Young's modulus of $\mathrm{Li}_{2} \mathrm{~S}_{-} \mathrm{P}_{2} \mathrm{~S}_{5}$ sulfide solid electrolytes has been estimated to be in the range of $14-25 \mathrm{GPa}$ [14, 15] 
Table 1: Mechanical properties of solid electrolyte materials.

\begin{tabular}{|c|c|c|c|c|c|c|c|}
\hline & Compound & Processing Method & Young's Modulus & $\begin{array}{l}\text { Fracture } \\
\text { Toughness }\end{array}$ & Testing Method & Reference & $\begin{array}{l}\text { Conductivity } \\
\text { (room } \\
\text { temperature) }\end{array}$ \\
\hline LIPON & $\mathrm{Li}_{x} \mathrm{PO}_{y} \mathrm{~N}_{z}$ & $\begin{array}{l}\text { Amorphous LiPON } \\
\text { films magnetron } \\
\text { sputtered }\end{array}$ & $77 \mathrm{GPa}$ & & nanoindentation & 11 & $210^{-6} \mathrm{~S} \mathrm{~cm}^{-1}$ \\
\hline \multirow[t]{2}{*}{ Perovskite } & $\begin{array}{l}\mathrm{Li}_{0.33} \mathrm{La}_{0.57} \mathrm{TiO}_{3}- \\
\text { solid state }\end{array}$ & $\begin{array}{l}\text { Hot-pressing at } \\
1000^{\circ} \mathrm{C} \\
\text { relative density } \\
>95 \%\end{array}$ & $186 \pm 4$ & $\begin{array}{l}0.890-1.34 \\
M P a \mathrm{~m}^{0.5}\end{array}$ & nanoindentation & 12 & $\begin{array}{l}\text { bulk: } \sim 10^{-3} \mathrm{~S} \\
\mathrm{~cm}^{-1}\end{array}$ \\
\hline & $\begin{array}{l}\mathrm{Li}_{0.33} \mathrm{La}_{0.57} \mathrm{TiO}_{3}-\text { sol } \\
\text { gel }\end{array}$ & & $200 \pm 3 \mathrm{GPa}$ & $\begin{array}{l}0.890-1.31 \\
\mathrm{MPa} \mathrm{m}^{0.5}\end{array}$ & nanoindentation & & $\begin{array}{l}\text { total: } \sim 10^{-5} \mathrm{~S} \\
\mathrm{~cm}^{-1}\end{array}$ \\
\hline \multirow[t]{2}{*}{ Garnet } & $\begin{array}{l}\mathrm{Li}_{6.24} \mathrm{La}_{3} \mathrm{Zr}_{2} \mathrm{Al}_{0.24} \mathrm{O}_{11.98} \\
(\mathrm{LLZO})\end{array}$ & Hot pressed & $\begin{array}{l}150 \mathrm{GPa} \\
(\text { porosity }=0.03) ; \\
132.5 \mathrm{GPa} \\
(\text { porosity }=0.06 \text { ) }\end{array}$ & & $\begin{array}{l}\text { resonant } \\
\text { ultrasound } \\
\text { spectroscopy }\end{array}$ & 13 & $\sim 0.210^{-3} \mathrm{~S} \mathrm{~cm}^{-1}$ \\
\hline & cubic $\mathrm{Li}_{7} \mathrm{La}_{3} \mathrm{Zr}_{2} \mathrm{O}_{12}$ & $\begin{array}{l}\text { Relative density of } \\
\sim 9 \%\end{array}$ & $150 \mathrm{GPa}$ & & $\begin{array}{l}\text { resonant } \\
\text { ultrasound } \\
\text { spectroscopy }\end{array}$ & & $30^{-4} \mathrm{~S} \mathrm{~cm}^{-1}$ \\
\hline \multirow[t]{4}{*}{ Sulfide } & $\begin{array}{l}\mathrm{Li}_{2} \mathrm{~S}_{-} \mathrm{P}_{2} \mathrm{~S}_{5}-\text { hot } \\
\text { pressed }\end{array}$ & $\begin{array}{l}\text { Sintering at } 360 \\
\mathrm{MPa} \text { and } \\
\text { temperatures } \\
20-190^{\circ} \mathrm{C}\end{array}$ & $18-25 \mathrm{GPa}$ & & $\begin{array}{l}\text { ultrasound velocity } \\
\text { measurement and } \\
\text { compression test }\end{array}$ & 14 & $\begin{array}{l}310^{-4} \mathrm{~S} \mathrm{~cm}^{-1} \text { (for } \\
\text { fully dense } \\
\text { material) }\end{array}$ \\
\hline & $\begin{array}{l}\mathrm{Li}_{2} \mathrm{~S}_{-} \mathrm{P}_{2} \mathrm{~S}_{5} \text { - cold } \\
\text { pressed }\end{array}$ & $\begin{array}{l}\text { Sintering at } 180-360 \\
\text { MPa and room } \\
\text { temperature }\end{array}$ & 14-17 GPa & & & & \\
\hline & $\mathrm{Li}_{2} \mathrm{~S}-\mathrm{P}_{2} \mathrm{~S}_{5}$ & & $18.5 \pm 0.9 \mathrm{GPa}$ & $\begin{array}{l}0.23 \pm 0.04 \\
\mathrm{MPa} \mathrm{m}^{0.5}\end{array}$ & nanoindentation & 15] & \\
\hline & $\mathrm{Li}_{10} \mathrm{GeP}_{2} \mathrm{~S}_{12}$ & & $37.19 \mathrm{GPa}$ & & $\begin{array}{l}\text { Atomistic } \\
\text { simulation }\end{array}$ & [16] & $1.210^{-2} \mathrm{~S} \mathrm{~cm}^{-1}$ \\
\hline
\end{tabular}

Such a low stiffness has been regarded as favorable for the design of bulk-type batteries [51. However, we show that compliant solid electrolytes (with Young's moduli in the order of $\mathrm{E}_{S E}=15 \mathrm{GPa}$ ) are more prone to micro-cracking. Solid electrolytes deform by stretching and shearing in response to the particles' volume change. The nonlinear formulation of the mechanical equilibrium quantifies the difference in deformation and stress patterns associated with varying the SE's stiffness. A linear model, which would predict that stress scales with Young's modulus, would not capture the the microstructural effects that we describe below.

We compare the evolution of damage for several values of electrolyte's fracture energy $\left(G_{c}=0.25-4.0 \mathrm{~J} \mathrm{~m}^{-2}\right)$ and volume expansion of the active material $(7.5 \%, 15 \%$ and 30\%). A cohesive model postulates that fracture energy is released gradually as the crack opens. The CZM differs from the Griffith model wherein energy is released instantaneously. The gradual release presumes some cohesion between the separating flanks of a crack. Generally, the traction decays with increasing separation until it vanishes at a critical opening displacement. The fracture energy represents the integral of the traction-separation curve and it is treated as a model-parameter. In our analyses, cracking is prevented only in those cases for which the electrolyte's fracture energy $G_{c} \geq 4.0 \mathrm{~J} \mathrm{~m}^{-2}$ and the particles' total volumetric expansion is $\Delta V \leq 7.5 \%$. In all the other cases, the model predicts some extension of mechanical degradation.

Recent studies have analyzed the properties of the interface between solid electrolytes and electrode materials 52 54. In particular, Zhu et al. 52 have identified voltage-stability ranges for many SE materials and predicted decomposition products of the interface reaction. The formation of an interface layer is expected to affect lithium transfer kinetics. Thick interface layers may also modify the local mechanical response. However, further studies are needed to characterize the interfacial properties. We believe the assumption of a perfectly coherent and stable interface to be appropriate for the scope of this study.

In the following section we illustrate the model and discuss the results in detail.

\section{Modeling of fracture in all-solid-state battery electrodes}

\section{Methods}

In one common design of ASSBs, the positive and negative electrodes are composites of active electrode-particles embedded in a solid-matrix admixture of ionic and electronic conducting materials. Negative electrodes are, in most cases, produced and assembled in the delithiated state. During the first charge, the anode particles tend to expand as they intercalate Li (experimentally measured 


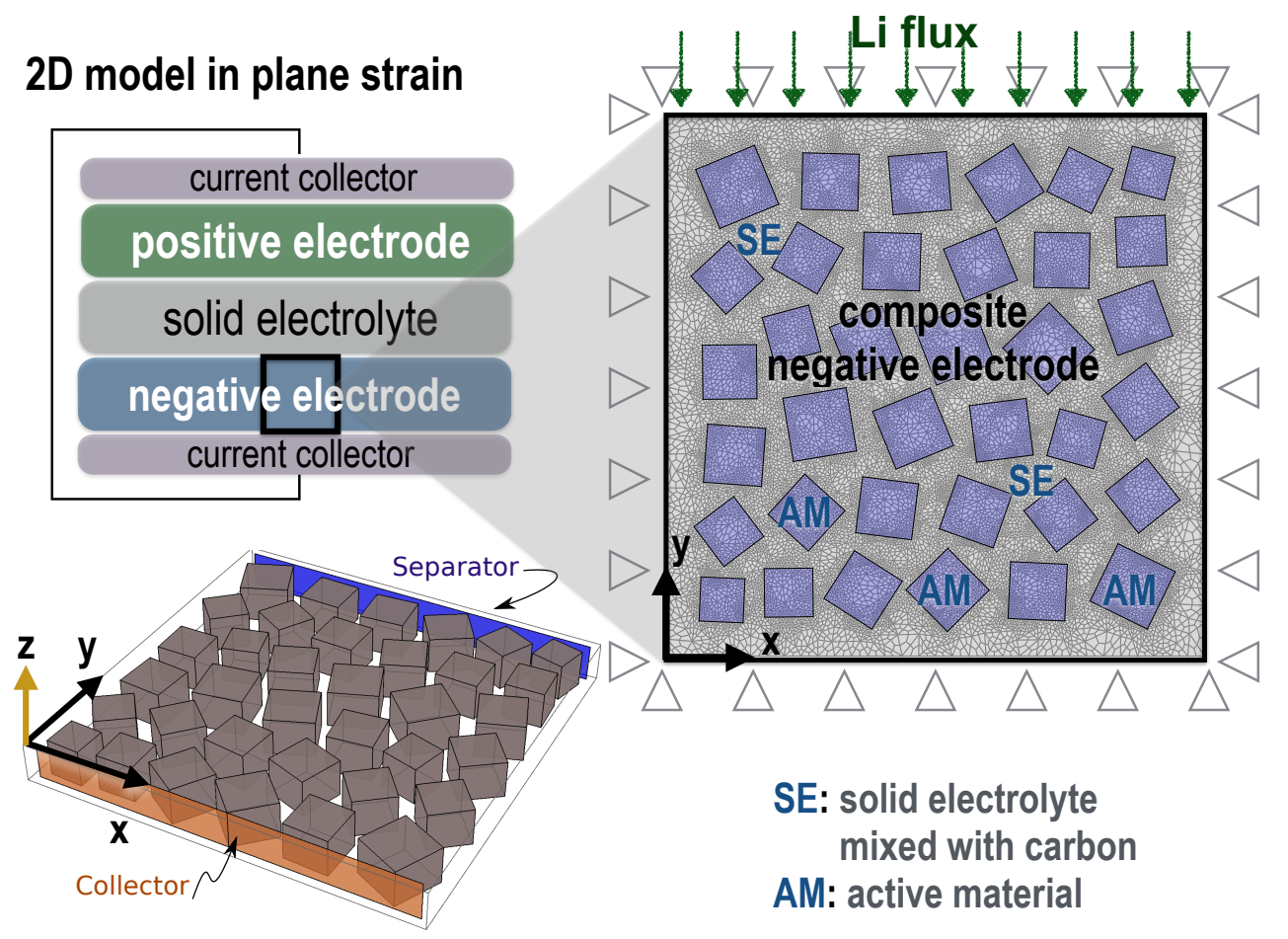

Figure 1: Geometry, discretization and boundary conditions of a finite element model of a composite electrode. Electrode particles are embedded in a mixed conductor, consisting of a solid electrolyte and an electronically conductive additive.

Vegard's strains for many Li-storage compounds are summarized in Tables 1.1 and 1.2 of Woodford's thesis. [55, and in Table 1 of Mukhopadhyay \& Sheldon [56]). Constrained by the surrounding SE matrix, the particles will be in compression. The mechanical stress and degradation caused by swelling of electrode particles is modeled as follows.

A finite element (FE) code was implemented according to the theoretical continuum model described by Bucci et al. 9. A representative microstructural arrangement of a distribution of particle sizes and its FE discretization with linear quadrilateral elements are represented in Fig. 1. The FE mesh is representative of a portion of the composite negative electrode (square highlighted in Fig. 1). The section extends from the current collector to the separator. The direction parallel to the Li flux is marked with $y$ in Fig. 1. Because of the large computational cost of a full 3D analysis, the system is modeled in $2 \mathrm{D}$ under the assumption of plane strain. According to the $2 \mathrm{D}$ plane strain model, the electrode particles are allowed to expand in the $x y$ plane, but not in the $z$ direction. Plane strain is typically employed for a thin plate embedded in a thicker sample. This is a realistic assumption for a typical bulktype electrode. The $2 \mathrm{D}$ model is expected to correctly capture trends in stress and fracture.

The grid is managed with the deal.II finite-element library [57, 58. The microstructure includes 36 randomly oriented square particles in a region of dimensions $11 \mu \mathrm{m} \times$ $11 \mu \mathrm{m}$. The particle's position and size distribution follow from a centroidal Voronoi tessellation. The average particle size is $1 \mu \mathrm{m}$. The area ratio of active material is about $50 \%$-a typical volume ratio for commercial Li-ion batteries is about $50-60 \%$. We consider shapes with sharp corners (the squares chosen here) to be a more realistic representation of particles than circles-see for instance Fig. 6 of Sakuda et al. [51] and 3D image reconstruction of $\mathrm{LiCoO}_{2}$ particles of Harris et al. [59]. Flaws and stresses are more likely to accumulate near sharp corners.

At a given time step, the electrochemical-mechanical problem is solved employing a Newton-Raphson iterative algorithm. At each iteration, displacements, Li concentration and diffusion potential are calculated, as the solution to three equations that couple the electro-, chemo-, and mechanical fields. We model the matrix as a homogenized admixture of ionic and electronic conductors. The constitutive behavior for the electrode and the electrolyte material is assumed to be elastically and diffusively isotropic. Materials are assumed to have a linear elastic constitutive behavior. The solid electrolyte material is considered to have zero Vegard's strain. Input parameters for this problem are summarized in Table. 2 (the variables listed appear in the equations discussed in Bucci et al. [9]).

The CZM of fracture is based on an intrinsic historydependent constitutive behavior [10]. The flux across the interface is irreversibly set to zero at the onset of fracture. The "intrinsic" CZM approach is based on the preinsertion of cohesive elements along potential crack paths. Therefore, fracture is allowed to propagate along a subset 
of finite element interfaces. Those interfaces lie along crack patterns that run between particles. The pre-insertion of cohesive elements along potential crack paths restrict the propagation of fracture. An alternative approach, called "extrinsic", is based on the insertion of cohesive elements on the fly, only at the interfaces where the fracture criterion is met. However, this method requires changes in the mesh topology, and it is not suitable for parallel computing. We assume that the placement of the $\mathrm{CZ}$ elements in regions of high shear would not differ from the extrinsic approach.

Galvanostatic tests are performed by applying a constant and uniform lithium flux (corresponding to a constant current density) at the separator interface (top edge in Fig. 1. The spatial variability of the current density at the separator depends on specific features of the electrochemical cell, such as electrode thickness and tortuosity. Polarization effects in proximity of the separator could be modeled by treating both sides of the electrochemical cell. A zero flux is assumed on the remaining edges.

For the mechanical problem, zero horizontal displacement Dirichlet boundary conditions are applied on the left and right boundaries. The displacement is considered fully constrained (in the vertical direction) on the top edge by the presence of the SE, and at the bottom edge by packaging or neighbor cells. We expect the volume change of the active material to be accommodated by the deformation of the SE matrix in ASSBs. This is similar to what Harris et al. 59] observed (by digital image correlation techniques) in graphite electrodes, where most of graphite's swelling was compensated by reducing the electrode porosity. Harris et al. showed that the average strain of a graphite electrode was only about $0.2 \%$ during lithiation, an order of magnitude smaller than graphite's chemical expansion.

\section{Results}

For the baseline example, we choose a solid electrolyte material, having Young's modulus $\mathrm{E}_{S E}=15 \mathrm{GPa}$ and bulk fracture energy $G_{c}=1.0 \mathrm{~J} \mathrm{~m}^{-2}$. These are representative values a sulfide $\mathrm{SE}$ material. In order to reveal behavior over a wide range of Vegard's expansion, the intercalation compound was allowed to have up to $30 \%$ volumetric expansion at full lithiation. However, our simulation shows that fracture initiates when particles have changed their volume by only $3 \%$, a value that encompasses the behavior of many intercalation compounds.

A sequence of snapshots in Fig. 2 illustrate the state of charge (left column), the hydrostatic Cauchy stress (right column). Cracks propagating within the solid electrolyte material are represented as black lines. Thickening of the black lines represents progressive interface separation and accumulation of damage.

On average, compressive stress arises as a consequence of the particles' chemical expansion because the entire system is constrained by the surrounding material. The simulation shows small regions of tensile stress developing in the area near the particles' corners (rust-colored areas in
Table 2: Material parameters for problems in Section 2

\begin{tabular}{ll}
\hline Input value & Description \\
\hline$F=96485.3365 \mathrm{C} \mathrm{mol}^{-1}$ & Faraday's constant \\
$R=8.314 \mathrm{~J} \mathrm{~K}^{-1} \mathrm{~mol}^{-1}$ & gas constant \\
$T=298 \mathrm{~K}$ & temperature \\
$M_{E l}=10^{-15} \mathrm{~m}^{2} \mathrm{~s}^{-1}$ & mobility of Li in the electrode material \\
$M_{S E}=10^{-13} \mathrm{~m}^{2} \mathrm{~s}^{-1}$ & mobility of Li in the solid electrolyte material \\
$c_{\text {max }_{A M}}=1$ & maximum relative number of mole of Li per mole of electrode compound \\
$c_{\text {max }}=0.25$ & maximum relative number of mole of Li per mole of solid electrolyte \\
$i=10 \mathrm{~A} \mathrm{~m}^{2}$ & maximum relative number of mole of Li per mole of solid electrolyte \\
$\gamma_{L i}=1$ & activity coefficient \\
$\nu=0.3$ & Poisson's ratio for both materials \\
$\beta_{A M}=0.1$ & relative lattice constant for Li in electrode material \\
$\beta_{S E}=0$ & relative lattice constant for Li in the solid electrolyte material \\
$E_{A M}=100 \mathrm{GPa}$ & Young's modulus of the electrode material \\
$E_{S E}=15 \mathrm{GPa}$ & Young's modulus of the solid electrolyte material \\
$G_{C}=1.0 \mathrm{~J} \mathrm{~m}$ & fracture energy of the bulk solid electrolyte material \\
$\delta_{0}=5 \mathrm{~nm}$ & opening displacement at the onset of damage \\
$\delta_{c r}=20 \cdot \delta_{0}$ & critical opening displacement (complete interface separation) \\
\hline
\end{tabular}

the contour plots of Fig. 2. The misalignment of these corners creates matrix shear- and tensile-stresses.

Each snapshot in Fig. 2 represents the lithiation and stress state at subsequent states of charge. For all the numerical tests, the current density is held constant at $1 \mathrm{~mA} \mathrm{~cm}^{-2}$ (a typical current density for commercial Liion batteries). Time is indicative of state of charge, unless the evolution of stress varies significantly among tests. This a consequence of the electro-chemo-mechanical coupling 60.

As the state of charge progresses, the pressure in the particles increases. In Fig. 2c, the compressive stress in the active material is higher than $1 \mathrm{GPa}$ (for particles that have stored approximately $50 \%$ of their total Li capacity). The stress-strain curve measured by Sakuda et al. 14 shows a linear-elastic behavior for $\mathrm{Li}_{2} \mathrm{~S}-\mathrm{P}_{2} \mathrm{~S}_{5}$ in compression. Our simulations predict the compressive stress in the electrolyte to lie within the linear elastic range of $0-200$ $\mathrm{MPa}$, as measured by Sakuda et al.

We performed a series of numerical tests by varying the fracture energy of the SE material in the range $G_{c}=$ $0.25-4.0 \mathrm{~J} \mathrm{~m}^{-2}$. To our knowledge, the only experimental data on the fracture toughness of a sulfide SE material is reported by McGrogan et al. 15. McGrogan and coauthors measured the toughness $\mathrm{K}_{I c}=0.23 \pm 0.04 \mathrm{MPa} \mathrm{m}^{0.5}$ via nano-indentation of a glassy $\mathrm{Li}_{2} \mathrm{~S}_{-} \mathrm{P}_{2} \mathrm{~S}_{5}$ sample. Such a fracture toughness corresponds to the fracture energy $\mathrm{G}_{c}=2.8 \pm 1.8 \mathrm{~J} \mathrm{~m}^{-2}$, given the Young's modulus $\mathrm{E}_{S E}=$ $18.5 \pm 0.9 \mathrm{GPa}$ measured by McGrogan et al.

The relative crack length (extension of fracture normalized with respect to electrode thickness) is illustrated in Fig. 3 as it evolves with respect to time. For each curve in Fig. 3 it is possible to identify three stages: a) onset of fracture, b) approximately constant propagation rate, and $c$ ) decreasing propagation rate up to saturation. As expected, crack nucleation is delayed in tougher materials. The propagation rate (slope of the curve in stage $b$ ) increases with decreasing fracture energy. In all the examples fracture propagates in a stable fashion (rather than sudden failure). A plateau in the curves of Fig. 3] indicates crack-growth saturation. In the cases with lower fracture energy, stage $c$ may be biased by the availability of crack patterns-even if about $10 \%$ of the pre-inserted cohesive in- 

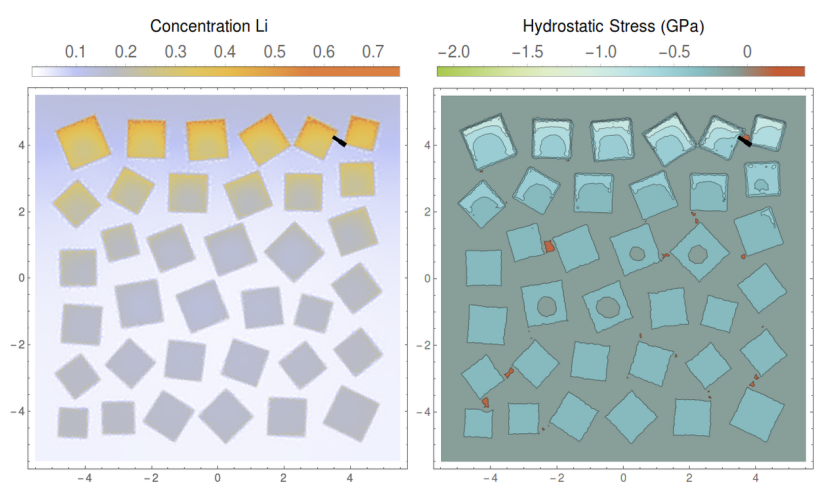

(a) $\mathrm{t}=150 \mathrm{~s}, \mathrm{SOC}=0.115641$
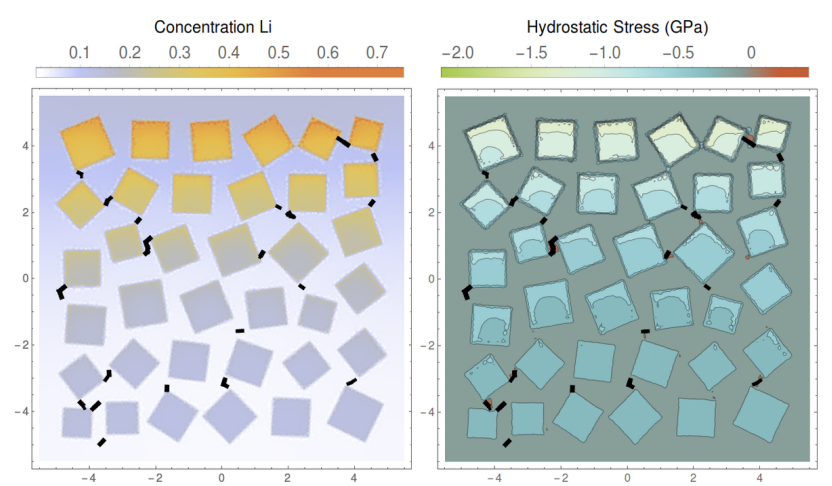

(b) $\mathrm{t}=400 \mathrm{~s}, \mathrm{SOC}=0.168185$
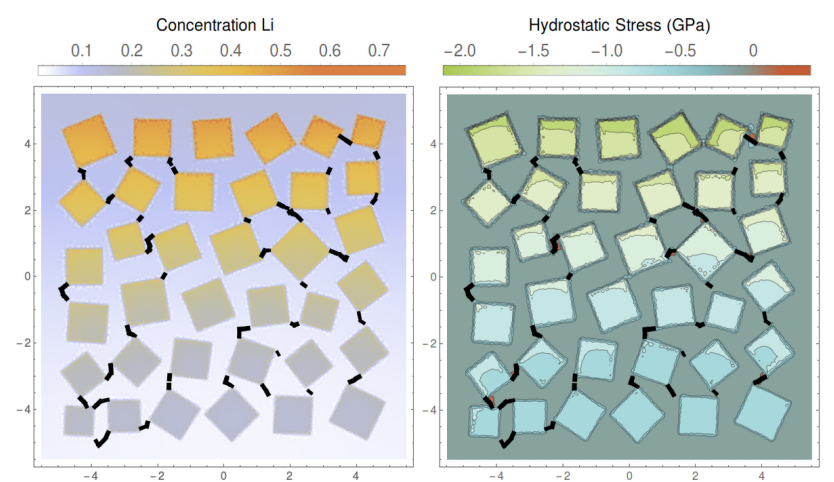

(c) $\mathrm{t}=900 \mathrm{~s}, \mathrm{SOC}=0.273068$

Figure 2: Evolution of damage in the solid electrolyte material at subsequent states of charge. With increasing $\mathrm{Li}$ content, the active material undergoes chemical expansion. As the particles stress-free strain increases, compressive stress develops in most of the microstructure. However, a few regions in proximity of the particles corner are under tensile stress (brown regions in the right contour plots above). This tension grows large enough to initiate fracture in the solid electrolyte matrix, This phenomenon is captured in the simulation by the cohesive elements. Cracks (marked with black lines) propagate from corner to corner, cutting off diffusion paths for Li within the electrolyte.

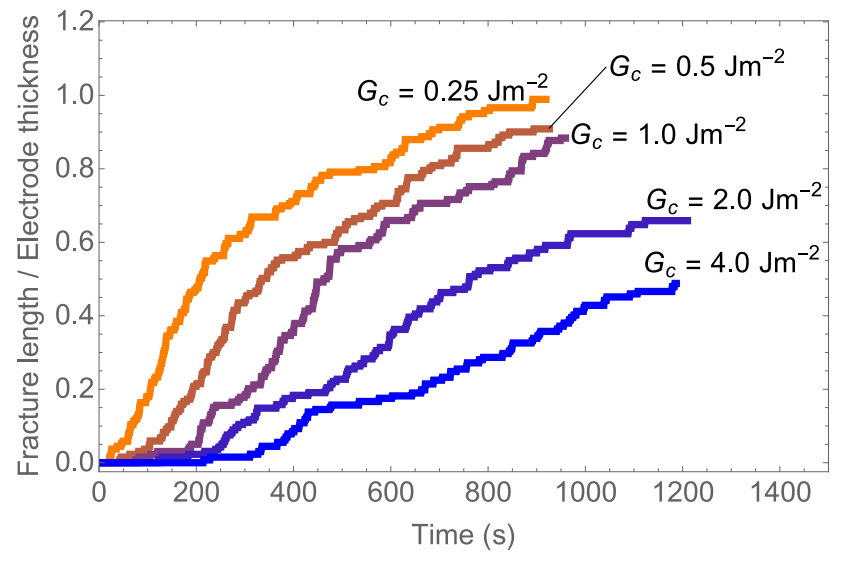

Figure 3: The extension of micro-cracks within the solid electrolyte material has been computed by a mesoscale finite element model. The curves represent five cases of SE fracture energies in the range $G_{c}=0.25-4.0 \mathrm{~J} \mathrm{~m}^{-2}$. The propagation rate (slope of the curve in stage b) increases with decreasing fracture energy.

terfaces remain unfractured. The pre-insertion of cohesive elements in specified locations is a possible shortcoming of this model. As shown in Fig. 3, solid electrolytes with fracture energy up to $4 \mathrm{~J} \mathrm{~m}^{-2}$ are predicted to fracture when electrode particles undergo $30 \%$ of intercalation-induced swelling .

We explore the dependence of the predicted damage on the electrolyte elastic properties. We consider electrolytes with Young's moduli $E_{S E}=25 \mathrm{GPa}$ and $E_{S E}=50 \mathrm{GPa}$ and $E_{S E}=150 \mathrm{GPa}$ in addition to the baseline case $\left(E_{S E}=15 \mathrm{GPa}\right)$. The Young's modulus $E_{S E}=150 \mathrm{GPa}$ is representative of a garnet solid electrolyte material (see Table 11). The results in Fig. 4 illustrate the inverse relationship between the velocity of crack propagation and the electrolyte's stiffness. A more compliant solid electrolyte tends to deform more by stretching and shearing in response to the particles' volume change. Regions of tensilestress form in the SE matrix where fracture is promoted. An electrolyte with stiffness closer to that of the active material (here the Young's modulus of the electrode material is set to $E_{A M}=100 \mathrm{GPa}$ ) tends to develop higher compressive stress, but undergoes lower tension. If the problem is considered from a linear elasticity perspective, these results may seem counter-intuitive. However in the non-linear formulation, the large displacements give rise to tensile and shear stresses, particularly large in the case of compliant SEs.

In order to identify conditions that prevent mechanical degradation, we consider active materials with lower volume change associated with changes in Li stoichiometry. Furthermore, we raised the solid electrolytes fracture energy up to $G_{c}=4.0 \mathrm{~J} \mathrm{~m}^{-2}$. The model predicts that fracture is suppressed, for active materials with $7.5 \%$ Vegard's expansion and solid electrolytes with the fracture energy $G_{c}=4.0 \mathrm{~J} \mathrm{~m}^{-2}$ and Young's modulus $E_{S E}=15 \mathrm{GPa}$. 


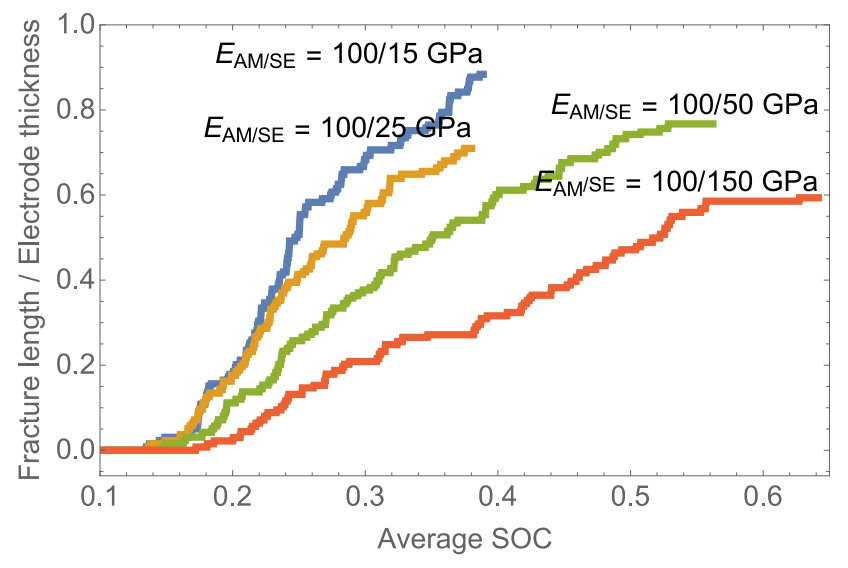

Figure 4: The extension of crack (normalized with respect to the electrode thickness) is plotted for three cases characterized by different Young's moduli of the solid electrolyte material, i.e., $E_{S E}=15,25,50 \mathrm{GPa}$. Other input parameters are the same of the baseline case (see Table 2), and the Young's modulus of the active material remain fixed at $E_{S E}=100 \mathrm{GPa}$. As the stiffness of the SE increases, a lower velocity of fracture propagation is predicted. A stiffer SE tends to contain the chemical expansion of the active material. Shearing and tension -responsible for crack growth- are less likely to arise in a less deformable material.

Thus, mechanical damage is predominantly dependent on SE fracture properties, as most Li-storage compounds have Vegard's expansion below 7.5\% [55, 56.

Results from several tests are collected in Fig. 5, where we observe the overlapping of two groups of curves. These curves are marked with a and b in Fig. 5, and represent the tests with SE fracture energy $G_{c}=1.0 \mathrm{~J} \mathrm{~m}^{-2}$ and $G_{c}=0.25 \mathrm{~J} \mathrm{~m}^{-2}$. The results can be explained by referring to the system's energy balance. As the particle's volume increases upon lithiation, the solid electrolyte volume is forced to shrink because the electrode's volumeaveraged deformation is zero. Hydrostatic pressure developing in the electrode and electrolyte materials scales linearly with volume change. The pressure is also proportional to the materials' bulk moduli. It follows that the elastic energy stored in the electrolyte becomes four times larger when the active material's expansion is doubled. If the fracture energy required to open new cracks is also four times larger, fracture propagation rate remains the same. In order to characterize the dependence on the total energy, both stored elastic and fracture energy, we define a new dimensionless parameter for all-solid-state electrodes: $\mathcal{G}=0.5 k_{S E}\left(3 \beta_{A M} A_{A M}\right)^{2} /\left(H G_{C}\right)$. In the definition of $\mathcal{G}$, $k_{S E}$ is the SE bulk modulus, $\beta_{A M}$ the Vegard's parameter ( $3 \beta_{A M}$ is the volumetric expansion rate) of the active material, $H$ is the electrode's thickness, and $A_{A M}$ is the area of active material. The two overlapping curves for the case $a$ and the the case $b$ in Fig. 5 are characterized by the same value of $\mathcal{G}$. Therefore, the dimensionless parameter
$\mathcal{G}$ can be used to generalize the results presented here.

\section{Conclusions}

Electro-chemo-mechanical FEM simulations capture the onset and propagation of damage in a solid-state composite electrode. Fracture is prevented if electrode-particle's expansion is lower than $7.5 \%$ and the solid-electrolyte's fracture energy higher than $G_{c}=4 \mathrm{~J} \mathrm{~m}^{-2}$ (under the assumption of SE Young's modulus $\mathrm{E}_{S E}=15 \mathrm{GPa}$ ). This condition restricts the choice of electrolyte based on its fracture properties, while most intercalation oxides have volume expansion below 7.5\% [55]. We refer here to the average volume change of a poly-crystalline material-Vegard's parameters can be largely anisotropic, this is for instance the case of graphite.

Here we refer to the aver Intercalation-induced expansion of the active material is constrained in dense solidstate electrodes and electrolytes are prone to mechanical degradation. The particles and SE together create a microstructure-the shape of particles and their proximity within the microstructure determine fracture. Microstructural inhomogeneities, such as particle-to-particle misalignment and particle asperities are sufficient to cause tensile and shear stress in the solid electrolyte matrix.

The simulations predict fracture to propagate in a stable fashion (rather than abruptly). As expected, crack nucleation is delayed in tougher materials. The propagation rate and the final extension of cracks also decrease with increasing electrolyte fracture energy.

Perhaps counter-intuitively, the analyses show that compliant solid electrolytes (with Young's modulus in the order of $\mathrm{E}_{S E}=15 \mathrm{GPa}$ ) are more prone to micro-cracking. Shearing and stress arise if the particles have surface asperities or the stress-fields of nearby particles interact. Because compliant SEs allow for large deformations they are more likely to develop localized tension and fracture. A non-linear kinematics model is required to predict this effect which contradicts the speculation that sulfide SEs are more suitable for the design of bulk-type batteries than oxide SEs [51].

To our knowledge, this work is the first to investigate mechanical reliability of all-solid state batteries. The results presented have implications for the battery powerdensity. Fracture in solid Li-ion conductors represents a barrier for Li transport and accelerate the decay of rate performance.

Reliability of ASSBs will depend on the elastic energy associated with intercalation-induced strain, the solid-electrolyte fracture energy and the geometry of the microstructure. Therefore, a simple design rule can be based on the dimensionless parameter $\mathcal{G}=0.5 k_{S E}\left(3 \beta_{A M} A_{A M}\right)^{2} /\left(H G_{c}\right)$ representing the ratio between elastic and fracture energies. We predict the integrity of elastic-brittle solid-state electrolytes to be preserved when the condition $\mathcal{G}<1000$ is met. 


\section{Acknowledgments}

The work was supported by the grant DE-SC0002633 funded by the U.S. Department of Energy, Office of Science.

\section{References}

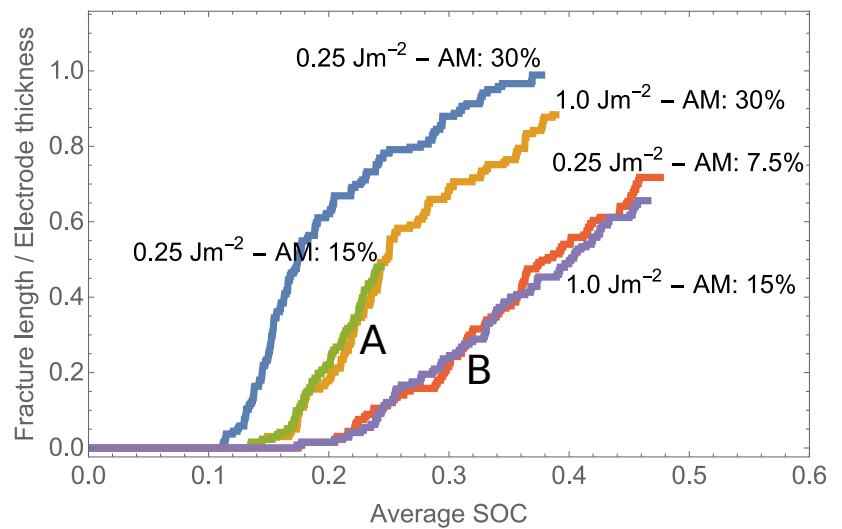

Figure 5: Various combination Vegard's parameters of the active material and SE fracture energy are analyzed. The overlap of two sets of results is observed. They correspond to the two cases marked as a

a) $30 \%$ volume change of the active material and SE fracture energy $G_{c}=1.0 \mathrm{~J} \mathrm{~m}^{-2}$

a) $15 \%$ volume change of the active material and SE fracture energy $G_{c}=0.25 \mathrm{~J} \mathrm{~m}^{-2}$

and other two cases, marked as b

b) $15 \%$ volume change of the active material and SE fracture energy $G_{c}=1.0 \mathrm{~J} \mathrm{~m}^{-2}$

b) $7.5 \%$ volume change of the active material and $\mathrm{SE}$ fracture energy $G_{c}=0.25 \mathrm{~J} \mathrm{~m}^{-2}$

The interpretation of this outcome is based on the system's energy balance. As the particles volume increases upon lithiation, the solid electrolyte volume is forced to shrink. Here we assume the volume-averaged deformation of the entire region to be zero. A less restrictive assumption would allow for the electrode's thickness to evolve with state of charge. In linear eleasticity, the hydrostatic pressure developing in both materials scales linearly with their volume change -proportionally to their bulk modulus. It follows that the elastic energy stored in the SE material become four times larger, when the particles' expansion is doubled. If the fracture energy required to open new cracks is also four times larger, fracture propagates at the same rate.
[1] K. Takada, "Progress and prospective of solid-state lithium batteries," Acta Materialia, vol. 61, no. 3, pp. $759-770,2013$.

[2] J. Li, C. Ma, M. Chi, C. Liang, and N. J. Dudney, "Solid electrolyte: The key for high-voltage lithium batteries," Advanced Energy Materials, vol. 5, no. 4, pp. 1-6, 2015.

[3] J. G. Kim, B. Son, S. Mukherjee, N. Schuppert, A. Bates, O. Kwon, M. J. Choi, H. Y. Chung, and S. Park, "A review of lithium and non-lithium based solid state batteries," Journal of Power Sources, vol. 282, pp. 299-322, 2015.

[4] V. Thangadurai, S. Narayanan, and D. Pinzaru, "Garnet-type solid-state fast li ion conductors for li batteries: critical review," Chem. Soc. Rev., vol. 43, pp. 4714-4727, 2014.

[5] E. Quartarone and P. Mustarelli, "Electrolytes for solid-state lithium rechargeable batteries: recent advances and perspectives," Chem. Soc. Rev., vol. 40, pp. 2525-2540, 2011.

[6] K. Takada, N. Ohta, and Y. Tateyama, "Recent Progress in Interfacial Nanoarchitectonics in Solid-State Batteries," Journal of Inorganic and Organometallic Polymers and Materials, pp. 205-213, 2014.

[7] M. Tatsumisago, M. Nagao, and A. Hayashi, "Recent development of sulfide solid electrolytes and interfacial modification for all-solid-state rechargeable lithium batteries," Journal of Asian Ceramic Societies, vol. 1, pp. 17-25, mar 2013.

[8] Y. Suzuki, K. Kami, K. Watanabe, A. Watanabe, N. Saito, T. Ohnishi, K. Takada, R. Sudo, and N. Imanishi, "Transparent cubic garnet-type solid electrolyte of al2o3-doped li7la3zr2o12," Solid State Ionics, vol. 278, pp. 172 - 176, 2015.

[9] G. Bucci, Y.-M. Chiang, and W. Carter, "Formulation of the coupled electrochemical-mechanical boundary-value problem, with applications to transport of multiple charged species," Acta Materialia, vol. 62, pp. 33-51, 2016.

[10] G. Bucci and W. Carter, Mechanics of Materials. Micromechanics in electrochemical systems (in production). Springer, 2016.

[11] E. G. Herbert, W. E. Tenhaeff, N. J. Dudney, and G. M. Pharr, "Mechanical characterization of LiPON films using nanoindentation," Thin Solid Films, vol. 520, no. 1, pp. 413-418, 2011.

[12] Y.-H. Cho, J. Wolfenstine, E. Rangasamy, H. Kim, H. Choe, and J. Sakamoto, "Mechanical properties of the solid Li-ion conducting electrolyte: $\mathrm{Li}_{0.33} \mathrm{La}_{0.57} \mathrm{TiO}_{3}$," Journal of Materials Science, vol. 47, pp. 5970-5977, 2012.

[13] J. E. Ni, E. D. Case, J. S. Sakamoto, E. Rangasamy, and J. B. Wolfenstine, "Room temperature elastic moduli and Vickers hardness of hot-pressed LLZO cubic garnet," Journal of Materials Science, vol. 47, pp. 7978-7985, 2012.

[14] A. Sakuda, A. Hayashi, and Y. Takigawa, "Evaluation of elastic modulus of $\mathrm{Li}_{2} \mathrm{~S}-\mathrm{P}_{2} \mathrm{~S}_{5}$ glassy solid electrolyte by ultrasonic sound velocity measurement and compression test," Journal of the Ceramic Society of Japan, vol. 121, no. 11, pp. 946-949, 2013.

[15] F. P. McGrogan, T. Swamy, S. R. Bishop, E. Eggleton, L. Porz, X. Chen, Y.-M. Chiang, and K. J. V. Vliet, "Compliant yet brittle mechanical behavior of $\mathrm{Li}_{2} \mathrm{~S}_{-} \mathrm{P}_{2} \mathrm{~S}_{5}$ lithium-ion conducting solid electrolyte," Advanced Energy Materials, p. 1602011, 2017.

[16] Z. Q. Wang, M. S. Wu, G. Liu, X. L. Lei, B. Xu, and C. Y. Ouyang, "Elastic properties of new solid state electrolyte material $\mathrm{Li}_{1} 0 \mathrm{GeP}_{2} \mathrm{~S}_{1} 2$ : A study from first-principles calculations," International Journal of Electrochemical Science, vol. 9, no. 2, pp. 562-568, 2014. 
[17] W. H. Woodford, Y.-M. Chiang, and W. C. Carter, "Electrochemical shock of intercalation electrodes: a fracture mechanics analysis," Journal of The Electrochemical Society, vol. 157, no. 10, pp. A1052-A1059, 2010.

[18] T. K. Bhandakkar and H. Gao, "Cohesive modeling of crack nucleation under diffusion induced stresses in a thin strip: Implications on the critical size for flaw tolerant battery electrodes," International Journal of Solids and Structures, vol. 47, no. 10, pp. $1424-1434,2010$.

[19] A. F. Bower and P. R. Guduru, "A simple finite element model of diffusion, finite deformation, plasticity and fracture in lithium ion insertion electrode materials," Modelling and Simulation in Materials Science and Engineering, vol. 20, no. 4, p. 045004, 2012 .

[20] S. Renganathan, G. Sikha, S. Santhanagopalan, and R. E. White, "Theoretical analysis of stresses in a lithium ion cell," Journal of The Electrochemical Society, vol. 157, no. 2, pp. A155-A163, 2010.

21] R. E. García, Y.-M. Chiang, W. Craig Carter, P. Limthongkul, and C. M. Bishop, "Microstructural modeling and design of rechargeable lithium-ion batteries," Journal of The Electrochemical Society, vol. 152, no. 1, pp. A255-A263, 2005.

[22] C.-W. Wang and A. M. Sastry, "Mesoscale modeling of a li-ion polymer cell," Journal of The Electrochemical Society, vol. 154, no. 11, pp. A1035-A1047, 2007.

[23] S. Golmon, K. Maute, and M. L. Dunn, "Numerical modeling of electrochemical-mechanical interactions in lithium polymer batteries," Computers \& Structures, vol. 87, no. 23-24, pp. 1567 - 1579, 2009

[24] M. Zhu, J. Park, and A. M. Sastry, "Fracture analysis of the cathode in li-ion batteries: A simulation study," Journal of The Electrochemical Society, vol. 159, no. 4, pp. A492-A498, 2012.

[25] R. T. Purkayastha and R. M. McMeeking, "An integrated 2-d model of a lithium ion battery: the effect of material parameters and morphology on storage particle stress," Computational Mechanics, vol. 50, no. 2, pp. 209-227, 2012.

[26] C. Miehe, H. Dal, L.-M. Schänzel, and A. Raina, "A phasefield model for chemo-mechanical induced fracture in lithiumion battery electrode particles," International Journal for $\mathrm{Nu}$ merical Methods in Engineering, pp. n/a-n/a, 2015. nme.5133.

[27] K. Aifantis and J. Dempsey, "Stable crack growth in nanostructured li-batteries," Journal of Power Sources, vol. 143, no. 12, pp. $203-211,2005$.

[28] I. Ryu, J. W. Choi, Y. Cui, and W. D. Nix, "Size-dependent fracture of si nanowire battery anodes," Journal of the Mechanics and Physics of Solids, vol. 59, no. 9, pp. 1717 - 1730, 2011.

[29] K. Aifantis and S. Hackney, "Mechanical stability for nanostructured sn- and si-based anodes," Journal of Power Sources, vol. 196, no. 4, pp. $2122-2127,2011$.

[30] S. Kalnaus, K. Rhodes, and C. Daniel, "A study of lithium ion intercalation induced fracture of silicon particles used as anode material in li-ion battery," Journal of Power Sources, vol. 196, no. 19 , pp. $8116-8124,2011$

[31] Y. Xia, T. Wierzbicki, E. Sahraei, and X. Zhang, "Damage of cells and battery packs due to ground impact," Journal of Power Sources, vol. 267, pp. 78 - 97, 2014.

[32] X. Zhang and T. Wierzbicki, "Characterization of plasticity and fracture of shell casing of lithium-ion cylindrical battery," Journal of Power Sources, vol. 280, pp. 47 - 56, 2015.

[33] F. Hao and D. Fang, "Reducing diffusion-induced stresses of electrode-collector bilayer in lithium-ion battery by pre-strain," Journal of Power Sources, vol. 242, pp. 415 - 420, 2013.

[34] H. B. Chew, B. Hou, X. Wang, and S. Xia, "Cracking mechanisms in lithiated silicon thin film electrodes," International Journal of Solids and Structures, vol. 51, no. 23-24, pp. $4176-$ 4187, 2014.

[35] A. Drozdov, "Constitutive equations for self-limiting lithiation of electrode nanoparticles in li-ion batteries," Mechanics Research Communications, vol. 57, pp. $67-73,2014$.

[36] J. Ye, Y. An, T. Heo, M. Biener, R. Nikolic, M. Tang, H. Jiang, and Y. Wang, "Enhanced lithiation and fracture behavior of silicon mesoscale pillars via atomic layer coatings and geometry design," Journal of Power Sources, vol. 248, pp. 447 - 456, 2014.

[37] L. Greve and C. Fehrenbach, "Mechanical testing and macromechanical finite element simulation of the deformation, fracture, and short circuit initiation of cylindrical lithium ion battery cells," Journal of Power Sources, vol. 214, pp. $377-385$, 2012 .

[38] Y. Wang, Y. He, R. Xiao, H. Li, K. Aifantis, and X. Huang, "Investigation of crack patterns and cyclic performance of tisi nanocomposite thin film anodes for lithium ion batteries," Journal of Power Sources, vol. 202, pp. 236 - 245, 2012.

[39] M. Pharr, Z. Suo, and J. J. Vlassak, "Variation of stress with charging rate due to strain-rate sensitivity of silicon electrodes of li-ion batteries," Journal of Power Sources, vol. 270, pp. 569 $-575,2014$

[40] J. K. Min, M. Stackpool, C. H. Shin, and C.-H. Lee, "Cell safety analysis of a molten sodium-sulfur battery under failure mode from a fracture in the solid electrolyte," Journal of Power Sources, vol. 293, pp. 835 - 845, 2015.

[41] C. Zhang, S. Santhanagopalan, M. A. Sprague, and A. A. Pesaran, "Coupled mechanical-electrical-thermal modeling for short-circuit prediction in a lithium-ion cell under mechanical abuse," Journal of Power Sources, vol. 290, pp. 102 - 113, 2015.

[42] Z. Ma, Z. Xie, Y. Wang, P. Zhang, Y. Pan, Y. Zhou, and C. Lu, "Failure modes of hollow core-shell structural active materials during the lithiation-delithiation process," Journal of Power Sources, vol. 290, pp. 114 - 122, 2015.

[43] C. Zhang, S. Santhanagopalan, M. A. Sprague, and A. A. Pesaran, "A representative-sandwich model for simultaneously coupled mechanical-electrical-thermal simulation of a lithiumion cell under quasi-static indentation tests," Journal of Power Sources, vol. 298, pp. 309 - 321, 2015.

[44] S. S. Damle, S. Pal, P. N. Kumta, and S. Maiti, "Effect of silicon configurations on the mechanical integrity of silicon-carbon nanotube heterostructured anode for lithium ion battery: A computational study," Journal of Power Sources, vol. 304, pp. 373 $-383,2016$.

[45] I. Laresgoiti, S. Kabitz, M. Ecker, and D. U. Sauer, "Modeling mechanical degradation in lithium ion batteries during cycling: Solid electrolyte interphase fracture," Journal of Power Sources, vol. 300, pp. 112 - 122, 2015.

[46] I. Ryu, S. W. Lee, H. Gao, Y. Cui, and W. D. Nix, "Microscopic model for fracture of crystalline si nanopillars during lithiation," Journal of Power Sources, vol. 255, pp. 274-282, 2014.

[47] Y. Dai, L. Cai, and R. E. White, "Simulation and analysis of stress in a li-ion battery with a blended limn2o4 and lini0.8co0.15al0.05o2 cathode," Journal of Power Sources, vol. 247, pp. 365 - 376, 2014.

[48] H. Yang, F. Fan, W. Liang, X. Guo, T. Zhu, and S. Zhang, "A chemo-mechanical model of lithiation in silicon," Journal of the Mechanics and Physics of Solids, vol. 70, pp. 349 - 361, 2014.

[49] B. Dimitrijevic, K. Aifantis, and K. Hackl, "The influence of particle size and spacing on the fragmentation of nanocomposite anodes for li batteries," Journal of Power Sources, vol. 206, pp. $343-348,2012$.

[50] S. Lee, J. Yang, and W. Lu, "Debonding at the interface between active particles and $\{$ PVDF $\}$ binder in li-ion batteries," Extreme Mechanics Letters, vol. 6, pp. 37 - 44, 2016.

[51] A. Sakuda, A. Hayashi, and M. Tatsumisago, "Sulfide Solid Electrolyte with Favorable Mechanical Property for All-SolidState Lithium Battery," Scientific reports, vol. 3, p. 2261, jan 2013.

[52] Y. Zhu, X. He, and Y. Mo, "First principles study on electrochemical and chemical stability of solid electrolyte-electrode interfaces in all-solid-state li-ion batteries," J. Mater. Chem. A, vol. 4, pp. 3253-3266, 2016.

[53] W. D. Richards, L. J. Miara, Y. Wang, J. C. Kim, and G. Ceder, "Interface stability in solid-state batteries," Chemistry of $\mathrm{Ma}$ terials, vol. 28, no. 1, pp. 266-273, 2016.

[54] S. Wenzel, D. A. Weber, T. Leichtweiss, M. R. Busche, J. Sann, 
and J. Janek, "Interphase formation and degradation of charge transfer kinetics between a lithium metal anode and highly crystalline $\mathrm{Li}_{7} \mathrm{P}_{3} \mathrm{~S}_{1} 1$ solid electrolyte," Solid State Ionics, vol. 286, pp. $24-33,2016$.

[55] W. H. Woodford, Electrochemical Shock: Mechanical Degradation of Ion-Intercalation Materials. PhD thesis, Massachusetts Institute of Technology, 2013.

[56] A. Mukhopadhyay and B. W. Sheldon, "Deformation and stress in electrode materials for Li-ion batteries," Progress in Materials Science, vol. 63, no. February, pp. 58-116, 2014.

[57] W. Bangerth, R. Hartmann, and G. Kanschat, "deal.II - a general purpose object oriented finite element library," ACM Trans. Math. Softw., vol. 33, no. 4, pp. 24/1-24/27, 2007.

[58] W. Bangerth, T. Heister, L. Heltai, G. Kanschat, M. Kronbichler, M. Maier, B. Turcksin, and T. D. Young, "The deal.II library, version 8.2," Archive of Numerical Software, vol. 3, 2015.

[59] S. J. Harris and P. Lu, "Effects of Inhomogeneities -Nanoscale to Mesoscale- on the Durability of Li-Ion Batteries," The Journal of Physical Chemistry C, vol. 117, no. 13, pp. 6481-6492, 2013.

[60] G. Bucci, T. Swamy, S. Bishop, B. W. Sheldon, Y.-M. Chiang, and W. C. Carter, "The effect of stress on battery-electrode capacity," Journal of The Electrochemical Society, vol. 164, no. 4, pp. A645-A654, 2017. 